\title{
Kombucha and Kefir are Foods of the 21st Century: A Opinion
}

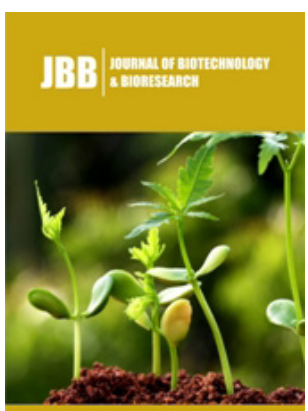

*Corresponding author: Karina Teixeira Magalhães-Guedes, Federal University of Bahia - UFBA, Brazil

Submission: 侮 July 10, 2019

Published: 漹July 16, 2019

Volume 2 - Issue 2

How to cite this article: Karina T, M-G, Talita An, da A, Rosane F S. Kombucha and Kefir are Foods of the 21st Century: A Opinion. J Biotech Biores.2(2). JBB.000532.2019.

Copyright@ Karina Teixeira MagalhãesGuedes, This article is distributed under the terms of the Creative Commons Attribution 4.0 International License, which permits unrestricted use and redistribution provided that the original author and source are credited.
Karina Teixeira, Magalhães-Guedes ${ }^{1 *}$, Talita Andrade, da Anunciação ${ }^{1}$ and Rosane Freitas Schwan²

${ }^{1}$ Federal University of Bahia-UFBA, Brazil

${ }^{2}$ Federal University of Lavras-UFLA, Brazil

\section{Opinion}

Kefir is a fermented milk product having slight acidic taste, carbonation, and aroma good. The kefir beverage contains a specific mixture of microorganisms (lactic bacteria, acetic bacteria e yeast) that reside in symbiotic manner in a kefiran polysaccharide matrix. Kefir grains (Figure 1) can be characterized as small cauliflower florets, having a length of $10-40 \mathrm{~mm}$, irregularly shaped, white to yellowish in color, having firm texture and slimy appearance. The kefir microorganisms have a capacity to produce organic acids, antibiotics, and numerous types of antimicrobials; these substances have a lethal effect on pathogenic microorganisms of the body. Kefiran is an exopolysachhardie component of kefir grain that has significant importance in human health and nutrition [1,2].

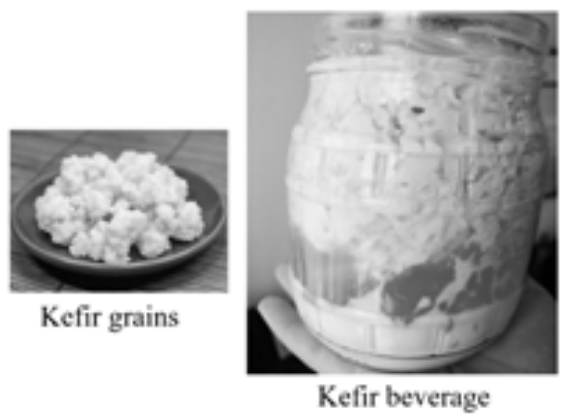

Figure 1: Kefir-grains and beverage.
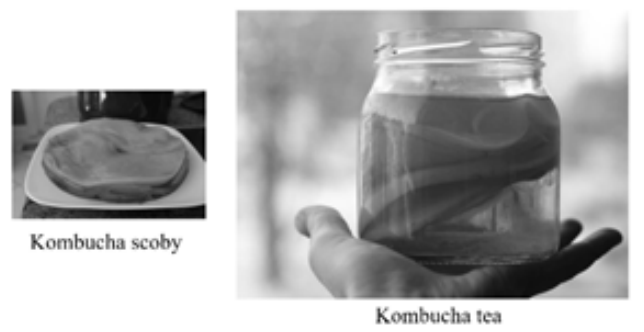

Figure 2: Kombucha-scoby and tea.

kefir beverage is being used as prophylactic to lessen the threat of allergy, gastrointestinal diseases, and hypertension [3]. Kefir beverages also find acceptance for infants and preschoolers as naturais diet. kefir is efficient in lowering infections of small intestine in young ones and infants. Based on these nutritional claim's kefir beverage can be classified as naturais probiotic resource.

Kombucha is a nutritive beverage obtained by the fermentation of the sugared tea with a probiotic culture (scoby (Figure 2)) of acetic bacteria, lactic bacteria and fungi, for its beneficial effects on human health. This nutritive beverage has been consumed in many countries for a very long time, and today interest is growing because scientific reports indicate that kombucha tea could prevent chronic diseases. Kombucha has a beneficial effect such as 
antibiotic properties, regulation of gastric, intestinal and glandular activities, relief of joint rheumatism, gout and hemorrhoids, positive influence on the cholesterol level, arteriosclerosis, toxin excretion and blood cleansing, diabetes, nervousness, and aging problems.

Nutritive ability of kombucha tea can be explained by the formation of iron and gluconic acid, which increases the level of blood hemoglobin and stimulates Adenosine Triphosphate (ATP) synthesis. Vitamin C synthesized by kombucha tea, can enhance absorption on nonheme (plant-derived) iron. Vitamin B group also synthesized by kombucha tea can promote the enzymatic activation for lipid and protein metabolism. The Central Oncological Research Unit in Russia have conducted population investigations on kombucha tea and have determined that consumption of this beverage on a daily basis has correlation with resistance to cancer [4]. The kombucha tea modulates immunity and prevents cancer proliferation at early phase of hormone-dependent tumor cell growth, due to the synergetic action of kombucha tea symbiosis. May have an effect against breast cancer. The potential health benefits of kombucha tea in humans are vast and potentially important for population health.
There is a growing trend to consume nutritional food products having health benefits among various segments of mark on every part of this globe. This desire directed the consumption of kefir and kombucha in daily diet. Due to high nutraceutical and therapeutic potential, kefir and kombucha are ranked at top position as foods of the $21^{\text {st }}$ century.

\section{References}

1. Amarasinghe H, Weerakkody NS, Waisundara VY (2018) Evaluation of 473 physicochemical properties and antioxidant activities of kombucha "tea fungus" during 474 extended periods of fermentation. Food Science and Nutrition 6(3): 659-665.

2. Magalhães-Guedes KT, Souza US, Silva MR, Santos FL, Nunes IL (2018) Production of rice cereal-based kefir beverage. African Journal of Biotechnology 17: 322-327.

3. Puerari C, Magalhães KT, Schwan RF (2012) New cocoa pulp-based kefir beverages: Microbiological, chemical composition and sensory analysis. Food Research International 48(2): 634-640.

4. Villarreal-Soto SA, Beaufort S, Bouajila J, Souchard JP, Taillandier P (2018) Understanding kombucha tea fermentation: A Review. Journal of Food Science 83(3): 580-588. 